\title{
DEMOCRATIZACIÓN: AVANCES Y RETROCESOS EN AmÉrica LATina
}

FRANCES HAGOPIAN*

Universidad de Notre Dame, Estados Unidos

Clase Magistral realizada por la profesora Frances Hagopian el 15 de noviembre de 2006 en el VIII Congreso Chileno de Ciencia Política organizado por la Asociación Chilena de Ciencia Política.

Señor Presidente Lagos, estimados invitados de honor, colegas chilenos, latinoamericanos, internacionales, amigos y amigas, y sobre todo, estudiantes:

\section{INTRODUCCIÓN: UN VIAJE PERSONAL}

Es más que un placer -es una profunda honra haber sido invitada a dictar esta clase magistral hoy frente al VIII Congreso de la Asociación Chilena de Ciencia Política, y me gustaría agradecer a Claudio Fuentes y a la Directiva, desde lo profundo de mi corazón, por esta distinción y oportunidad.

Para mí, personalmente, este es un momento de grandes emociones, un paso en un viaje que comenzó aquí en Chile hace 32 años. Desembarqué por primera vez en tierras latinoamericanas aquí en Chile, justo cuando el Presidente Lagos estaba en Carolina del Norte, la profesora Barbara Stallings trabajaba en su excelente libro sobre la economía política de tres gobiernos chilenos, mi amigo el Profesor Felipe Agüero sufría como víctima de un régimen bárbaro, y el profesor Arturo Valenzuela estaba escribiendo su trabajo sobre el colapso de la democracia chilena, una obra que sigue siendo el mejor tratamiento del tema que existe. En esa época tenía 20 años, casi no hablaba castellano, y no tenía ni idea de cómo hacer una investigación. Era una niña ingenua, tonta. Fue en 1974, y descendí del avión en una tierra ocupada por militares con ametralladoras. Me pareció que había descendido en el infierno. La tesis, sobre la oposición de la clase media al gobierno de la Unidad Popular, fue bastante mediocre. Pero resolví, ese verano, seguir estudiando la política comparada de América Latina. Mi carrera fue lanzada aquí en Chile. Y lo que es aun más significativo: aquí nació mi obsesión con la democracia, su quiebre, su reconstrucción y su calidad.

Entonces, cuando me llegó la invitación de Claudio, no tuve más que aceptar. Fue una oportunidad de compensar una deuda personal. $\mathrm{Y}$ hoy me gustaría agradecer a este país y a sus valiosos profesores que me ayudaron tanto en aquella época. Olvidé muchos de los nombres, pero no es posible olvidar su bondad. 
Es maravilloso ver este programa, más interesante que el de la Asociación Americana de Ciencia Política de agosto pasado, y, para mí, un anuncio de que la ciencia política en Chile está de vuelta, después de varios años cuando, podemos decir, perdió su posición de liderazgo en América Latina respecto de los brasileños y mexicanos. Tal renacimiento supone oportunidades, sobre todo, de tomar lo mejor de varias escuelas y paradigmas, y construir una ciencia política que mantiene un enfoque en preguntas relevantes, informadas por teoría, conscientes de la historia, pero que también emplea los métodos más avanzados que existen. Para jugar un papel en un debate internacional, está claro que uno no quiere ser el "furgón de cola". Pero, al mismo tiempo, hay que viajar en la misma tierra y hablar el mismo lenguaje.

Y si me permiten una palabra más: será difícil para Chile asumir este liderazgo, y seguir adelante, con apenas una mitad del conjunto de su talento nacional. No puede ser que haya solamente dos, o tres, o menos de cinco doctoras en ciencia política en la academia chilena (y que una sea uruguaya). Para las estudiantes en la audiencia: cuando yo resolví seguir con esta carrera, casi no había profesoras de ciencia política en los Estados Unidos. Como niña ingenua y tonta, ni pensé en las obvias barreras -los obstáculos institucionales y los preconceptos culturales-que tendría que superar en el futuro, ni en los círculos sutilmente cerrados que tuve que enfrentar. Pero aquí estoy, hoy, en un país que recién eligió una mujer como Presidenta de la Republica. A las mujeres pioneras, digo que sí, todo es posible, con dedicación y perseverancia; a los hombres, digo que ellas necesitan también una apertura institucional, el apoyo de mentores; en fin, merecen oportunidades. Formar profesoras universitarias es un paso indispensable para el futuro liderazgo de esta gran comunidad académica, y para la formación de las generaciones de ciudadanos que siguen.

\section{II. ¿QUÉ ES ESTE FENÓMENO? ¿LA TERCERA OLA DEMOCRATIZADORA? ¿CÓMO LA DESCRIBIMOS?}

Bueno, el tema de mi discurso hoy es la tercera ola democratizadora. ¿Qué es esta ola, que llegó a las costas latinoamericanas hace un cuarto de siglo? Comenzando en la República Dominicana en el año 1978, una dictadura cayó tras otra. Con la transferencia de la oficina de la presidencia del PRI al PAN en México en 2000, solamente Cuba y Haití persisten gobernados por regímenes autoritarios. Como enfatizamos mi colega Scott Mainwaring y yo en el libro La Tercera Ola Democratizadora en América Latina, es notable que esta transición se haya realizado durante una década "perdida" y otra de crecientes desigualdades. Después de setenta años de reinado de un partido-estado en México, de sesenta años en que ningún gobierno democrático finalizó su mandato en Argentina, y de una dictadura de veintiún años en un país de graves desigualdades como es Brasil, los sistemas democráticos en estos países hoy son sólidos, y han resistido graves desafíos como escándalos de corrupción y colapsos del sistema bancario. Aun más sorprendente es el proceso en un país como El Salvador, donde después de setenta mil muertos, la democracia ha comenzado a echar raíces.

Hemos aprendido mucho sobre la democracia en los años que lleva esta ola democratizadora. Hoy en día en América Latina las democracias de la tercera ola sobreviven, en su mayor parte, y de manera diferente de sus antecesoras en el pasado, por cinco razones claves. Primero, el mundo 
ha cambiado. La Guerra Fría acabó, el imperio de la Unión Soviética colapsó, y la democracia, como idea y como sistema de gobierno, ha triunfado sobre todos sus competidores. En nuestro hemisferio, los embajadores en la OEA invocaron la resolución 1080 en la crisis peruana de 1992 y para evitar otro autogolpe en Guatemala en 1993, y el MERCOSUR también jugó un papel clave en Paraguay en 1996, como señaló el profesor Arturo Valenzuela, para evitar un golpe de estado.

Segundo, hubo un cambio de mentalidades regionales. Para la izquierda, la experiencia tanto de la represión como del exilio impulsó un cambio de actitud sobre la democracia y el compromiso. Este fenómeno es tal vez mejor ilustrado por el caso chileno.

Tercero, y ligado a la segunda razón, con las reformas del mercado, la derecha también aceptó la democracia en gran parte, porque ya no tienen que temer a las políticas redistributivas radicales.

A esta lista podemos añadir una cuarta razón: la ruptura de la alianza entre elites y militares. Si tuviera que elegir un epíteto de la tercera ola democratizadora, sin duda, sería el título de un artículo de mi colega argentino Carlos Acuña sobre el quiebre de la alianza entre la clase empresarial argentina y los militares, Ilamado "Por qué el futuro no es más lo que era". Y, finalmente, aunque estos países no aceptaron la recomendación de Arturo Valenzuela de dejar de lado los sistemas presidenciales y adoptar sistemas parlamentarios, muchos implementaron otras reformas institucionales para mejorar el funcionamiento del sistema presidencial. Entre otros, hablo de la creación de institutos electorales autónomos, ajustes a los ciclos electorales que permiten elecciones presidenciales y legislativas simultáneas, y reformas en los sistemas electorales desde Bolivia hasta Chile.

Los avances, en pocas palabras, son impresionantes, y los cambios subyacentes a esta ola son de enorme significación. Pero, al lado de los éxitos y los avances, hay que admitir que la tercera ola lleva consigo también retrocesos. Las democracias parecen restringidas, incapaces de generar crecimiento y empleo estable y bien compensado, de proveer seguridad a las personas y consolidar el estado de derecho, de acabar con la pobreza y la marginalidad, de garantizar los derechos de ciudadanía y mejorar el legado de la desigualdad.

¿Es la tercera ola, entonces, algo para celebrar? ¿Son estas democracias el fin de un largo camino, sangriento, que ha recorrido el continente? ¿Ofrecen el potencial de mejorar la condición humana? ¿0 están estas democracias basadas en instituciones electorales formales, desiguales, agentes de fuerzas globalizadoras que responden cada vez más a las organismos multilaterales que a sus propios ciudadanos?

Hace 15 años, me hubiera parecido improbable abrir esta discusión. En aquel entonces había una tendencia, impulsada por muchos académicos de mi generación, a no cuestionar o criticar a las democracias, por miedo de repetir los errores de subestimar brutalmente los beneficios de democracias imperfectas, y como resultado, someter a la población a una noche larga y oscura de vida sin libertad. El gran cientista político norteamericano, Robert Dahl, comienza su clásico trabajo, Poliarquía, con el lamento de los italianos Mosca, Croce y Salvemini que no valorizaron lo suficiente la democracia parlamentaria, imperfecta como era, hasta cuando fue demasiado tarde y el dictador Mussolini y sus camisas negras ya habían marchado sobre Roma destrozando la débil democracia italiana. Además, para los norteamericanos, criticar a las democracias 
latinoamericanas es algo peligroso; crea la impresión de un acto de imperialismo. Aun cuando no sea la intención, implica una comparación entre las democracias latinoamericanas jóvenes e incompletas, con la democracia del norte, madura, ejemplar, y perfecta.

Cuestionar a las democracias electorales, insisto, no es la misma cosa que denigrarlas. Es correcto y justo analizar sus deficiencias y preguntar qué las puede fortalecer y mejorar, sin rechazarlas, y abrir la puerta a alternativas. $Y$ yo voy a compartir un secreto con ustedes: la democracia norteamericana no es perfecta (aunque mejoró la semana pasada).

En este contexto, un diálogo intergeneracional e internacional sobre las calidades y debilidades de estas democracias puede ser algo muy útil. La meta debe ser perfeccionarlas y no destrozarlas. Vale la pena dibujar el cuadro actual, identificar los retos que enfrentamos, y antes que nada, examinar los retrocesos de la tercera ola.

\section{EXAMINANDO LOS RETROCESOS}

Los retrocesos de la tercera ola son varios y distintos. A veces, son visibles en la forma de espectaculares fracasos institucionales -como los llamados "autogolpes" y las renuncias de presidentes electos, ya sea por causa de procesamientos o simplemente debido a protestas populares. Esto sería lo que el profesor Valenzuela ha llamado "presidencias fallidas". Algunos presidentes fueron procesados, como en el caso de Brasil, Venezuela, Ecuador y Paraguay, mientras que otros fueron alejados del poder por manifestaciones de la clase media y de movilizaciones indígenas, como en Ecuador, Bolivia, Argentina y otros países. En otros casos, los sistemas de partidos se han derrumbado. Los casos venezolano y peruano son ejemplos de este fenómeno.

Más recientemente han surgido varios presidentes representantes de la izquierda, que muchos en el mundo académico y el mundo político ven como manifestación del descontento popular. Justo la semana pasada, triunfó Daniel Ortega en las elecciones presidenciales de Nicaragua. El retorno de los sandinistas en algunos círculos forma parte de un padrón preocupante de surgimiento de una nueva izquierda, y más peligroso aún, del fortalecimiento de un nuevo eje de gobiernos de izquierda en América Latina, a veces llamados neopopulistas, encabezados por Hugo Chávez (o Fidel Castro) y que incluye Evo Morales, Ollanta Humala, y tal vez Manuel Antonio López Obrador: nadie sabe con certeza.

En otros casos, o tal vez en otros momentos, los retrocesos son más bien sutiles. Los electores manifiestan su repugnancia al votar por un político o un partido "outsider", o directamente al no votar. Estas son democracias que cumplen con la definición formal de democracias electorales, pero que no gozan de apoyo popular. De hecho, en promedio, apenas la mitad de los latinoamericanos están de acuerdo en que la democracia es la mejor forma de gobierno. Estos niveles casi no llegan a dos quintos de la población en Brasil y Guatemala. En estos países, a pesar de que la presión crece, la verdadera crisis es evitada; el volcán no hace erupción. Como en un mal matrimonio, sobreviven, pero no con mucho entusiasmo. Son mediocres, nada más.

¿Es este desencanto algo preocupante? ¿Es peligroso para la democracia? ¿Es algo malo para la democracia? Después de todo, el procesamiento de un presidente corrupto en Brasil en 1992 fue 
algo para celebrar: -el triunfo de la Constitución y el principio de que nadie, aun el presidente, está por encima de la ley. Por otro lado, el hecho de cerrar las puertas del Congreso peruano, o de amenazar con lo mismo en Guatemala y Paraguay, es causa de inquietud, por lo menos, entre académicos. Otros casos no son tan claros. ¿Es la renuncia del presidente boliviano en 2003, por ejemplo, un paso atrás? Para algunos, sí, ya que significó la interrupción del sistema constitucional. Pero para otros fue la expresión del pueblo que el presidente haya perdido su base de apoyo y legitimidad. El paso atrás para algunos puede ser un paso hacia adelante para otros. Quizás somos testigos de un nuevo modelo de democracia, uno de tipo mayoritario, participativo, pero no necesariamente liberal.

Yo diría que la inestabilidad institucional es problemática, y que las democracias que no tienen gran apoyo entre sus ciudadanos, pero que todavía están de pie, no son necesariamente estables. El peligro es que estas democracias también pueden llegar a ser inestables en plena crisis. La línea que divide a los dos grupos, las que no tienen gran apoyo y las inestables, es fina. No entendemos bien los mecanismos que llevan a una democracia mediocre a ser una democracia en riesgo.

\section{MÁS ALLÁ DE LAS TRANSICIONES E INSTITUCIONES: UN PAPEL PARA LOS CIUDADANOS}

No entendemos bien las raíces y el rumbo del desencanto popular. Enfrentamos resultados de encuestas que no podemos explicar. Y creo que esta laguna en nuestro conocimiento existe, porque hemos buscado respuestas a preguntas de otra época. Buscamos la solución a los retos creados por instituciones débiles, como manejar demandas populares, atenuar la competencia partidaria, etc. Estos problemas, sí, condenaron a muerte las democracias de la segunda ola. Pero este enfoque obsesivo en aquellas preguntas nos ha desviado de los nuevos problemas y retos de la tercera ola.

Olvidamos que las democracias en la tercera ola son democracias de masas; y que los retos son diferentes a los de los años sesenta y setenta, de la misma manera que son distintos los remedios. En 2006, la política no puede ser más, en las palabras de Alexander Wilde, "conversaciones de caballeros”, y los partidos políticos no pueden ser más clubes de caballeros. El gran desafío hoy no es más el manejo de las demandas y la participación política. El problema principal de la tercera ola es el reto de la inclusión. Y si tengo razón, y el reto es la inclusión, tenemos que entender, entonces, los deseos, ansiedades y esperanzas de los ciudadanos más allá de las respuestas que dan en las encuestas de opinión pública, como nos advierte Augusto Varas.

Hasta ahora he hablado de los retrocesos y los retos de la tercera ola democratizadora como si fuesen iguales. Sin embargo, más allá de la izquierda "radical" de Hugo Chávez y Daniel Ortega - Ilamamos a ellos la izquierda 1-A- hay una izquierda 1-B, una izquierda que Washington considera "respetable": -de los Presidentes Lula en Brasil, Néstor Kirchner en Argentina, Tabaré Vásquez en Uruguay, y, sin duda, Michele Bachelet en Chile. Dadas las diferencias entre los países encabezados por las izquierdas 1-A y 1-B, y los distintos niveles de apoyo a la democracia, es evidente que tenemos que explicar la variación en la salud de estas democracias. Y esta variación nos ofrece la oportunidad de explicar diferencias en las causas y manifestaciones de retrocesos, como así también las posibles consecuencias. 


\section{EXPLICANDO RETROCESOS}

¿Cuáles son las raíces del desencanto popular, de la debilidad de las instituciones y de la precariedad de varias presidencias?

\section{1. ¿Es la economía, estúpido?}

Muchos dicen que la fortuna de la democracia hoy en día en América Latina sube y baja con la economía. Cuando el desempeño económico es bueno, cuando la economía y los salarios crecen, los precios son estables, y el desempleo es mínimo, los niveles de satisfacción con el gobierno del día son altos como es también la aprobación de la democracia. Esta hipótesis se puede resumir en la frase que hizo famoso al equipo del ex Presidente Bill Clinton durante la campaña electoral de 1992: "es la economía, estúpido". Esta frase fue invocada para recordar al personal a cargo de la campaña electoral que concentren su mensaje en la economía, que en aquella época era el problema más importante para el electorado. Se puede extender este argumento para incluir el desempeño gubernamental en otros campos importantes para el electorado, como la seguridad personal, la calidad de los sistemas de educación y de salud, etc.

Si es así, ¿por qué son tan débiles tantas economías? ¿Por qué vemos una verdadera epidemia de desempeño gubernamental mediocre? Algunos dicen que es por falta de voluntad política o por instituciones políticas que crean incentivos para políticas públicas disfuncionales. Por otro lado, muchos críticos plantean que los procesos de globalización y neoliberalismo son los responsables de la existencia de democracias mediocres y sin gran apoyo de sus ciudadanos, porque restringen la capacidad de los gobiernos de generar ingresos legítimos para invertir en servicios sociales y en formación de capital humano. Además, la lógica de la competencia a nivel mundial deprime los salarios y genera pobreza y desigualdades que, a su vez, amenazan a la democracia. Todos los presidentes, sean de extrema izquierda o de extrema derecha, tienen que responder a los "mercados".

En cierta manera, este argumento es lógico. Las probabilidades de que crezca el descontento son mayores cuando el desempleo y la pobreza aumentan. Pero ver el asunto a través de este único prisma es negar la historia y el presente. Una de las tasas de desempleo más altas en América Latina es la de Uruguay, que tiene también las tasas más altas de participación electoral en el hemisferio. La tesis que privilegia el desempeño económico como causa de la falta de apoyo popular a partidos y políticos tradicionales es demasiado limitada; ella no nos explica cuáles son las variables que condicionan el apoyo popular a regímenes democráticos en lugares de alto desempleo y desigualdad.

\section{2. ¿0 es la política, estúpido?}

A la diagnosis, "es la economía, estúpido", yo propongo una alternativa, que "es la política, estúpido". En este cuadro, el más grave desafío para la democracia deriva de la falta de representación política, de inclusión, de lazos fundamentales entre las organizaciones de la sociedad civil y la sociedad política. 


\section{EL PAPEL AMBIGUO DE LA PARTICIPACIÓN}

El modelo que plantea la primacía del desempeño económico supone que la asociación y movilización de ciudadanos complica la gobernabilidad. Este argumento encuentra inspiración en la escuela de la "cultura cívica", que definió como óptima cultura para la democracia a una con una correcta mezcla entre participación, por un lado, y deferencia y pasividad, por el otro. Los teóricos de los años setenta también plantearon que los gobiernos en las sociedades industrializadas avanzadas fueron amenazados por movimientos estudiantiles, de mujeres, de afroamericanos, o por cualquier corriente democrática radical. Aún hoy en día en los Estados Unidos efectuar un recorte en el gasto del gobierno es una pesadilla de hipermovilización de los que son llamados "intereses especiales"; ellos canalizan la presión pública de cualquier modo que permitan los medios de comunicación en el mundo moderno. Desde esta perspectiva, la participación política es algo a temer, a reducir. Mejor aislar a los técnicos de la presión popular y de las corrientes electorales, para que puedan tomar las decisiones correctas y difíciles.

En realidad, no hay un argumento fuerte, disponible, contrario a este. Los que están incómodos con esta conclusión hablan de compensación (o trade-offs). Admiten que la participación política puede complicar la gobernabilidad, pero sugieren que trae consigo otros beneficios. Las organizaciones voluntarias de la sociedad civil sirven como "escuelas de la democracia" en el sentido tocquevilliano. Yo estoy de acuerdo con el argumento que la participación conlleva estos beneficios, pero creo que también tenemos que construir otro argumento que plantee los beneficios de un concepto más amplio de ciudadanía.

Los teóricos que temieron la participación no consideraron que los ciudadanos que no participan en el proceso de formulación de demandas y en el debate sobre políticas públicas pueden volverse menos moderados, más propensos a impacientarse rápidamente cuando el desempeño gubernamental los decepciona, y más desencantados. Sin experiencia en la práctica política y sin el beneficio de discusiones políticas, los desencantados podrían ser más propensos a votar por políticos sin partido y que se presentan al electorado fuera de partidos, o a vincularse con movimientos radicales que tiene como fin derrumbar el sistema actual.

Vista desde la perspectiva de democracias que son vaciadas de apoyo popular, la crisis de la tercera ola, o por lo menos sus retrocesos, pueden ser entendidos como una "crisis de ciudadanía”, de participación y representación democrática. ¿Cuál es la solución para esta crisis? Más que participar, más allá de que la gente se asocie a organizaciones de la sociedad civil, hay que vincular las entidades civiles con los agentes políticos de representación. Pongamos por un momento los casos contrastantes de Argentina y Bolivia. En Argentina, después del colapso del sistema bancario en diciembre de 2001, los ciudadanos manifestaron, por supuesto, su enojo totalmente comprensible en el grito: "Que se vayan todos". Pero en ese momento, los estrechos lazos entre las asociaciones vecinales o los movimientos sociales y los punteros del Partido Justicialista salvaron la democracia, como argumenta Steve Levitsky. Por otro lado, en Bolivia, según la interpretación de René Mayorga, la sociedad civil movilizada se había desconectado de los partidos políticos. Sin la intermediación de los partidos, cada conflicto social llegó a ser un encuentro politizado entre movimiento y Estado, con la consecuencia posterior de la caída de dos presidentes. No es por casualidad que en los países en los que tiene éxito la izquierda 1-B, 
precisamente existan sociedades civiles fuertes ligadas a los partidos políticos; el PT en Brasil sirve como obvio ejemplo.

\section{MINIMIZANDO EL ESTADO Y EXTENDIENDO LA CIUDADANÍA}

Esta conexión es hoy más importante que nunca. Nos encontramos en un momento difícil, en cuanto hay que minimizar el Estado al mismo tiempo que las masas reclaman sus derechos de ciudadanía.

El neoliberalismo genera más demandas sociales de ciudadanía y democracia dirigidos a los gobiernos centrales justo cuando éstos pierden sus tradicionales prerrogativas y son cada vez menos capaces de responder y de proveer los bienes y los servicios reclamados. En algunos casos, el poder ha migrado hacia arriba, a jurisdicciones supranacionales y organizaciones transnacionales. En otros, ha sido privatizado. Y aun en otros ha sido devuelto hacia abajo, en esquemas descentralizados. Más allá de la promesa de llevar el gobierno más cerca del pueblo, no es tan claro que los gobiernos locales sean más eficaces y más democráticos que los nacionales. Y cuando los territorios coinciden con identidades étnicas, lingüísticas u otras identidades potenciales 0 reales, se pueden generar demandas orientadas a reclamar mayor autonomía.

Desde este punto de vista no es cierto que tengamos que temer a la izquierda. La historia contemporánea de América Latina nos enseña que los países sin izquierda electoral viable generan izquierdas más radicales, o un desánimo y desencanto entre la población que se constituye a base de apoyo para políticos que se clasifican como "antisistema". Ampliar la representación ideológica, debatir las políticas, dar expresión institucional a grupos de ciudadanos que el sistema político ha olvidado, no es peligroso. Al contrario, es peligroso y estúpido para una democracia postergar el futuro y negar los derechos de la ciudadanía.

Y, para terminar, el auge chileno. El modelo chileno. ¿Qué modelo? Chile parece lejos de todo esto y de estos retos. Chile ha sido en varias épocas un modelo para el continente -la Democracia Cristiana, la Vía Chilena, los reformas del mercado-y hoy, tal vez, Chile presenta un nuevo modelo, una democracia que funciona bien, que eligió una mujer, socialista, Presidenta de la República.

¿Es Chile, de hecho, un modelo para el resto de América Latina? ¿O es una excepción a una regla latina? ¿Cuál es la diferencia? Ser un modelo implica que uno abre un sendero que otros pueden caminar; ser excepción quiere decir que como quiera que sea deseable ese sendero, otros no tienen condiciones para seguirlo. ¿Es Chile un modelo, porque muestra los beneficios de la disciplina fiscal y el manejo prudente de la macroeconomía, de establecer las correctas prioridades para el gasto público, de invertir en la formación de capital humano, de reducir la pobreza, de modernizar la sociedad y moderar la política? ¿0 es una excepción, porque tuvo la oportunidad, muy costosa, pero una oportunidad al fin, de arreglar la economía antes de abrir la política, al recibir un sistema electoral y de partidos que -aunque impuesto por una dictadura- creó incentivos fuertes para moderar la competencia y evitar a la polarización? El profesor Dahl postuló que el sendero más favorable hacia la democracia, que él consideró ya cerrado en el mundo moderno, fue el de abrir la competencia entre elites antes de expandir la participación. ¿Ha Chile redescubierto la ventaja de esta secuencia? 
Claro que este debate supone que en Chile todo está bien con la democracia. Me parece que hace diez años tal afirmación hubiera sido problemática; existían los famosos "enclaves autoritarios" y la transición había sido declarada "finalizada" por las autoridades políticas, como escribió recientemente el profesor Felipe Agüero, pero no lo estaba para aquellos que seguían buscando justicia. Estas deficiencias son bastante obvias. Pero también el sistema de representación fue roto. Aun hoy este sistema no es de primera calidad: el sistema binomial es desproporcional, el número de representantes es bastante reducido, y aunque los alcaldes son electos, los "intendentes", los jefes del Ejecutivo en las 13 regiones administrativas, hasta la fecha, no lo son. Las provincias son administradas de manera similar por gobernadores designados y consejos de asesores económicos y sociales. Menoscabando la llamada rendición de cuentas vertical, los distritos electorales del Congreso no corresponden con estos distritos político-administrativos. Además, la participación política, sobre todo en los jóvenes, es bastante reducida y causa de graves inquietudes.

Si la democracia es reducible a las tasas bajísimas de desempleo, delincuencia y corrupción, Chile es segundo de ningún otro país en América Latina. Pero si la democracia demanda también la participación popular, la responsabilidad de las autoridades a las distintas preferencias de la población, de representar e incluir a los previamente subordinados en la esfera política, entonces, yo diría que Chile está en camino, y que ha dado grandes pasos en estos últimos cinco o seis años en abrir la política, pero que todavía no ha llegado a la tierra prometida. Es probable que desde hoy Chile vaya a enfrentar crecientes demandas de los mapuches, de las mujeres y tal vez de los jóvenes. Quizás con cautela inicialmente, pero con creciente confianza en sí misma, la sociedad civil, me imagino, vaya despertando y entrando en la escena política.

Nada está predeterminado. Aun con defectos de nacimiento, no es demasiado tarde para abrir el sistema e incluir y representar a los sin voz y presencia. Chile tiene hoy en día una inmensa oportunidad de construir sobre la base de un Estado que funciona una democracia representativa, participativa y buena. Ojalá que ustedes lleguen allí. Yo voy a acompañar el proceso hasta que se realice. Mucha suerte.

Y muchas gracias.

Frances Hagopian obtuvo su doctorado en el Massachusetts Institute of Technology. Actualmente es Michael P. Grace II Profesora Asociada de Estudios de América Latina en el Departamento de Ciencia Política, y Faculty Fellow en el Instituto Kellogg para Estudios Internacionales de la Universidad de Notre Dame, Estados Unidos. Sus áreas de estudio son la política comparada en América Latina y la economía política brasileña y del Cono Sur. Su libro más reciente es un trabajo co-editado con Scott Mainwaring titulado The Third Wave of Democratization in Latin America (Cambridge, 2005).

(E-mail: Hagopian.1@nd.edu) 
